
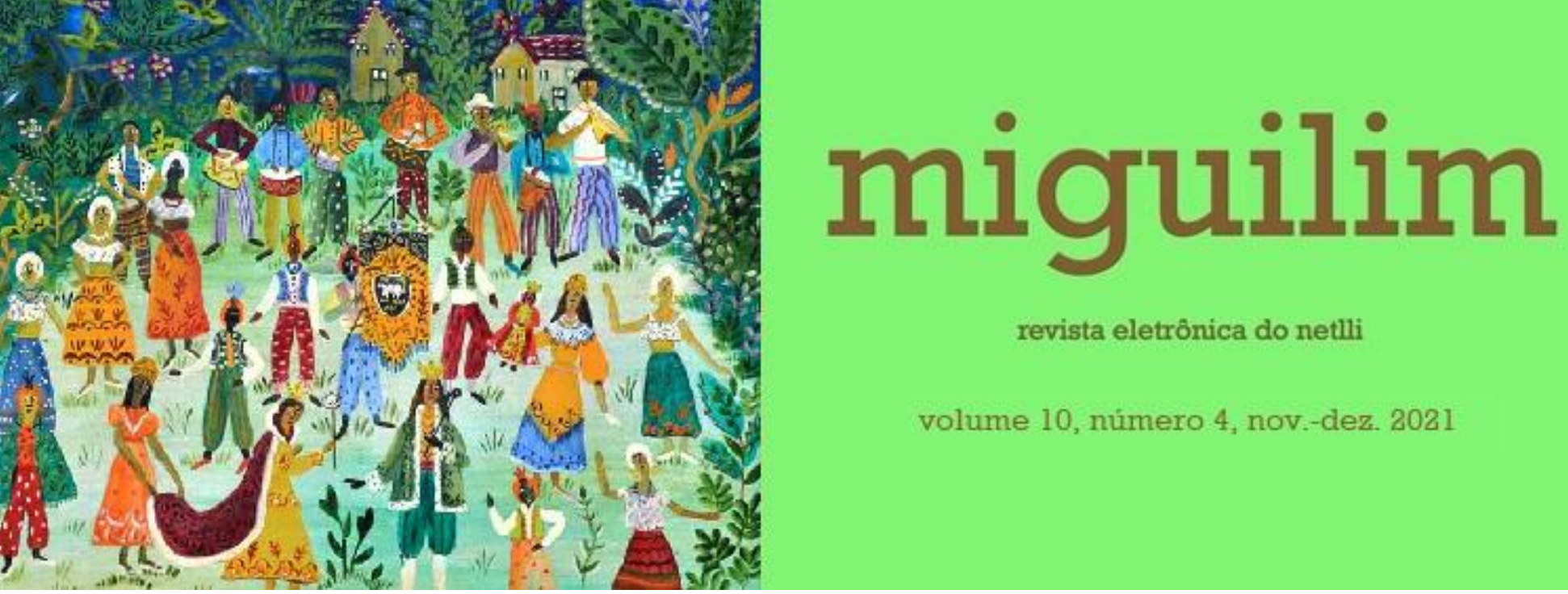

revista eletrônica do netlli

volume 10 , número 4 , nov.-dez. 2021

\title{
INTERNACIONALIZAÇÃO EM CASA E A FORMAÇÃO DE PROFESSORES DE INGLÊS: AVALIAÇÃO DE UMA EXPERIÊNCIA COM ETAS
}

\section{INTERNATIONALIZATION AT HOME AND ENGLISH TEACHERS' EDUCATION: EVALUATION OF AN} EXPERIENCE WITH ETAS

Juliane D'ALMAS

Universidade Estadual do Paraná, Brasil

Ana Cláudia CALDAS Universidade Estadual do Paraná, Brasil

Jaqueline Such de Melo GUIDES Universidade Estadual do Paraná, Brasil

RESUMO | INDEXAÇÃO | TEXTO | REFERÊNCIAS | CITAR ESTE ARTIGO | AS AUTORAS RECEBIDO EM 30/06/2021 • APROVADO EM 15/02/2022

DOI: https://doi.org/10.47295/mgren.v10i4.3620

\section{Resumo}

O presente estudo tem como objetivo avaliar a experiência com English Teaching Assistants (ETAs) da comissão Fulbright na formação de professores de inglês após o 
primeiro ano de execução do projeto em uma universidade estadual do Paraná fazendo uma ponte com o conceito de internacionalização em casa. A universidade em questão teve sua primeira experiência com a participação dos ETAs no curso de Letras Inglês no ano de 2018 e, ao final do referido ano aplicou-se um questionário a respeito das atividades realizadas para que os acadêmicos avaliassem-nas e assim, fosse possível planejar as ações do ano seguinte com novos ETAs. Um total de 58 alunos responderam ao questionário e, para esta investigação, focamos nas respostas a duas perguntas cujo objetivo era compreender a contribuição (se alguma), da participação das ETAs para a formação linguística e docente dos acadêmicos. Concluímos que, a maioria dos estudantes, viu uma contribuição significativa para sua formação com a participação das ETAs no curso e esta ação contribuiu fortemente para os avanços do processo de internacionalização do campus onde foi executada.

\section{Abstract}

This study aims at evaluating the experience with English Teaching Assistants (ETAs) of the Fulbright commission in the training of English teachers after the first year of the project at a state university in Paraná, making a connection to the concept of internationalization at home. The referred university had its first experience with the participation of ETAs in the English Language undergraduate course in 2018 and, at the end of that year, a feedback form was applied about the activities implemented so that academics could evaluate them and thus, it would be able to plan the actions of the following year with new ETAs. A total of 58 students answered the form and, for this investigation, we focused on the answers of two questions whose objective was to understand the contribution (if any) of the participation of ETAs to the linguistic and teaching training of academics. We conclude that most students saw a significant contribution to their education with the participation of ETAs in the course and this action strongly contributed to the progress of the internationalization process of the campus where it was implemented.

\section{Entradas para indexação}

Palavras-chave: Formação de professores. Internacionalização. ETAs. Comissão Fulbright. Língua inglesa.

Keywords: Teacher education. Internationalization. ETAs. Fulbright Commission. English language.

\section{Texto integral}

\section{Introdução}

A Comissão Fulbright, conhecida internacionalmente por distribuir bolsas de estudos para ensino de línguas tem como um de seus principais programas, o English Teaching Assistants (ETAs), onde jovens estadunidenses recém-formados no ensino superior podem se inscrever para serem professores visitantes em diversos países, inclusive no Brasil. 
Segundo a Fulbright ${ }^{1}$, o objetivo da inserção de professores colaboradores nativos da língua inglesa em cursos de Letras é de disseminar o idioma e também a cultura estadunidense nos países. Para os cursos de Letras, oportunizar o contato dos acadêmicos com falantes nativos pode ser uma prática que traz diversos benefícios, desde oportunizar aos alunos situações práticas de uso de suas habilidades linguísticas, bem como melhorar seus conhecimentos culturais, desmistificando mitos e verdades.

Considerando que, segundo perfis socioeconômicos dos estudantes dos cursos de Letras, a maioria do alunado vem de famílias de classe social média baixa, onde a possibilidade de realização de um intercâmbio é muito pequena, a interação com o nativo através do programa ETAs acaba sendo uma oportunidade única para os acadêmicos.

Tais vantagens para a comunidade local ainda vão ao encontro dos objetivos de internacionalização em casa (doravante $\mathrm{IeC}$ ) que consideramos primordiais para a realização de uma internacionalização inclusiva nas instituições de ensino superior (doravante IES) públicas.

A Universidade Estadual do Paraná (Unespar) campus Apucarana participou do edital para seleção das universidades em 2017 e foi uma das 40 instituições aprovadas, recebendo ETAs nos anos de 2018 e 2019. O projeto intitulado "Ensino, aprendizagem e formação inicial de professores de língua inglesa: contribuições de um English Teaching Assistant" tinha o objetivo de expandir o escopo de estudo da língua inglesa e da cultura estadunidense no curso de licenciatura em Letras-Inglês do campus mencionado, bem como contribuir para uma formação docente mais completa e atualizada por meio da participação de um assistente de ensino de língua inglesa - falante nativo - nas atividades curriculares e extracurriculares.

Neste artigo, iremos avaliar as primeiras impressões dos acadêmicos de Letras Inglês quanto a participação das ETAs no ano de 2018 e o impacto que essa participação teve no desenvolvimento profissional dos alunos e também fazer uma ponte com a questão da IeC.

Importante esclarecer que, em nenhum momento, o projeto escrito pela Unespar vê o falante nativo de inglês como superior ao falante não-nativo e principalmente, como um melhor professor. 0 intuito da interação é a de possibilitar aos nossos alunos um maior conhecimento de mundo, um aprimoramento das habilidades linguísticas, em especial a oralidade, e uma formação docente que propicie a criação de uma identidade pessoal e profissional que valorize a multiculturalidade.

Isto posto, o presente artigo se estrutura da seguinte maneira: na primeira seção, iremos explanar brevemente o conceito de internacionalização e internacionalização em casa, bem como a vantagem para a formação de professores de línguas, logo, iremos detalhar na metodologia os percursos metodológicos para coleta e análise dos dados. A seção de resultados traz a análise das respostas dos estudantes e, por fim, as considerações finais alcançadas.

\footnotetext{
${ }^{1}$ Informações retiradas de: https://fulbright.org.br/awards-for-us-citizens/english-teachingassistantship-eta/
} 


\section{Internacionalização em casa e formação de professores de línguas}

Uma das definições mais difundidas na literatura sobre o que é internacionalização, vem da pesquisadora Jane Knight (2003), a qual preconiza que internacionalização do ensino superior é "o processo de integrar uma dimensão internacional, intercultural e global nas propostas, funções e oferta da educação secundária" (p. 2). 0 termo internacionalização deriva de disciplinas e ações isoladas das universidades sob os nomes de intercâmbios, mobilidade acadêmica, estudar fora, estudos globais, educação multicultural, estudos internacionais, sendo os primeiros relacionados à mobilidade e os últimos referentes ao currículo. Nos anos 70 já tinham sido registradas publicações com o termo internacionalização, mas foi apenas nos anos 90 que este conceito substituiu de vez os estudos internacionais (De Wit, 2013).

0 processo de internacionalização das universidades já acontecia desde a Idade Média, quando alunos transitavam da Europa Central para a Itália e a França a fim de desenvolver estudos em várias universidades sucessivamente (vide proximidade geográfica). Naquele momento, todavia, a internacionalização se caracterizava sobretudo pela mobilidade de estudantes, sendo considerada um movimento extremamente elitista, o que perdurou por muito tempo, inclusive em outros países, a despeito do Brasil. Após a Revolução Industrial, houve maior valorização da educação superior, pois havia a ideia de que trabalhadores com maiores conhecimentos intelectuais geravam maior produção.

Quando findada a Segunda Guerra Mundial, surgiram diversos esforços para reconstruir as economias dos países envolvidos e o desenvolvimento de pesquisas passou a ser uma das prioridades. Sendo assim, acordos bilaterais e multilaterais entre universidades foram assinados. A globalização trouxe o avanço da tecnologia e maior agilidade na transmissão de conhecimentos e informações, o que acarretou modificações no conceito de internacionalização, haja vista que não era mais necessário realizar um intercâmbio para ter acesso a conhecimento produzido no exterior. Neste momento, a internacionalização ganhou seu caráter multifacetado. Segundo Baumvol e Sarmento:

A internacionalização se mostra como elemento definidor essencial para a configuração do ensino superior no século XXI, emergindo como um processo de rápida evolução. Percebe-se, ao longo dos anos, um aumento da complexidade deste processo ao redor do mundo diante das transformações decorrentes da globalização e das mudanças tecnológicas e econômicas, de mobilidade e de investimento privado em educação. (BAUMVOL; SARMENTO, 2016, p. 67).

Além da internacionalização por meio da mobilidade, o que muitas pessoas não sabem é que podemos realizar internacionalização universitária sem precisar sair de nosso país. Esta possibilidade tem sido nomeada como Internacionalização em Casa (doravante IeC), derivada do inglês, Internationalization at Home (IaH). De acordo com Jorge (2018), o objetivo da proposta é de incorporar nas atividades 
domésticas, ou locais, aspectos que, a priori, são pensados apenas para os casos de mobilidade internacional. Ainda definindo o termo, a pesquisadora pontua:

\begin{abstract}
A Internacionalização em Casa pode certamente ser um poderoso caminho para a educação para a cidadania global. A dimensão intercultural que marca ações dentro do próprio campus, sem exigir mobilidade física, é fator chave para se abrir espaços para falar da alteridade, das complexas relações globais e questões que aproximam o local do global, ao mesmo tempo que permitem um distanciamento crítico sobre interdependência de fenômenos que afetam as sociedades contemporâneas. (JORGE, 2018, p. 41).
\end{abstract}

Como ações de IeC podemos destacar mudanças referentes à elaboração de um currículo internacionalizado (ROBSON, 2017), o que envolve a "revisão de ambos os meios e materiais com os quais estudantes interagem" (p. 370). Em relação aos meios que as IES podem utilizar para fornecer experiências internacionalizadas estão a oferta de cursos de idiomas, de disciplinas com aulas em língua estrangeira (doravante LE), a inserção de bibliografias em LE em disciplinas, publicação de artigos em LE, participação de alunos e docentes em eventos internacionais, realização de eventos culturais e artísticos, projetos que tenham parcerias com professores de IES no exterior, entre tantas outras possibilidades.

Logo, a IeC surge não só como uma alternativa para aqueles que não têm condições de fazer um intercâmbio, mas também como uma possibilidade de inclusão de toda comunidade universitária no processo de internacionalização, caracterizando-se como uma ação de cunho social, que procura beneficiar a universidade em si e não somente uma minoria. Conforme De Wit, Leal e Unangst (2020) preconizam, este é um dos pilares da chamada internacionalização compreensiva (comprehensive internationalization), termo cunhado por Hudzik (2011).

Os conceitos de internacionalização e internacionalização em casa podem ser considerados relativamente novos, já que os mesmos têm sido mais profundamente estudados somente durante os últimos anos. Até pouco tempo atrás, não se sabiam realmente os impactos (positivos e negativos) que os processos de internacionalização podem exercer em uma comunidade e em uma IES. Por meio de recentes estudos, hoje conclui-se que as estratégias de internacionalização vão muito além de apenas movimentar estudantes entre países, e que tais ações afetam diretamente esferas educacionais, culturais, linguísticas e econômicas.

Com base em leituras sobre o assunto, pode-se entender que a internacionalização possui características particulares, complexas e geralmente equivocadas que se propagam por meio de dúvidas e mitos (KNIGHT, 2011; 2012). Dentre eles, os mais comuns são constituídos por meio de algumas crenças limitantes, como por exemplo, a de que a quantidade de alunos estrangeiros em uma universidade torna-a mais internacionalizada, ou de que a internacionalização só é possível se a mobilidade acadêmica ocorrer de um país para o outro. Tais conceitos contribuem para que a internacionalização seja vista apenas como uma 
consequência da globalização, e não como uma estratégia legítima de pesquisa e desenvolvimento nas instituições superiores.

A verdade é que quando feitas corretamente, as estratégias de internacionalização também são capazes de fortalecer e construir relações políticas nacionais e até mesmo regionais, não somente internacionais, como muitos pensam (KNIGHT, 2005). Afinal, o processo de internacionalização engloba dimensões interculturais, e isso também abrange trocas de culturas regionais e locais.

Isto posto, também é válido analisar e refletir sobre os impactos da internacionalização no Brasil. No país, estratégias de internacionalização do ensino superior começaram a ser implementadas a partir da década de 1990, mas no ano de 2013, o setor teve um drástico crescimento devido aos investimentos do governo nesta área, através do programa "Ciências Sem Fronteiras" (MAUÉS; BASTOS, 2017). Apesar de ser um dos programas que mais investiu na formação de alunos de graduação no exterior, ainda assim, atendeu menos de $1 \%$ da comunidade universitária (BAUMVOL; SARMENTO, 2016).

Contudo, os investimentos começaram a regredir no ano de 2016 com cortes nas bolsas destinadas a alunos de graduação, sendo ofertadas bolsas apenas para estudos em nível de pós-graduação. Segundo publicação feita pela revista Exame $^{2}$ no referido ano, o corte foi justificado pela falta de competência linguística dos acadêmicos e o elevado custo dos investimentos. Dizia-se à época, que o valor seria transferido para "um plano de melhoria no ensino de línguas para jovens em idade de Ensino Médio, pata capacitá-los para novas oportunidades", o que não aconteceu.

Tal fato coloca a IeC como extremamente essencial nos dias atuais por diversos fatores, tanto pela falta de investimentos em internacionalização por meio de mobilidade física (internationalization abroad - DE WIT; LEAL; UNANGST, 2020), ou pela necessidade de desenvolvimento de competência intercultural por parte dos alunos, ou ainda pela importância da formação linguística da comunidade acadêmica.

No caso desta pesquisa, fazemos uma ponte entre IeC e formação de professores. Ou seja, como a participação das ETAs na licenciatura em Letras Inglês contribui para a formação docente dos acadêmicos. Mikulec (2014) afirma que "há uma necessidade de desafiar professores em pré-serviço a olhar para além do seu ambiente imediato, para uma arena global maior" (p. 7). Isto é, futuros professores de inglês precisam ter uma noção do uso do idioma e de aspectos culturais que transcendam o livro didático, por exemplo. Ademais, segundo a autora:

... a internacionalização na formação de professores não somente fornece uma oportunidade de desenvolver a auto consciência global, mas também permite um maior entendimento de questões do mundo que podem levar a um comprometimento com a ação. (MIKULEC, 2014, p.11).

\footnotetext{
${ }^{2}$ Informações retiradas de notícia publicada pela revista Exame acessada via endereço: https://exame.com/brasil/o-corte-do-ciencia-sem-fronteiras-em-numeros/
} 
Sendo assim, a participação de ETAs no curso proporciona este contato com a cultura do outro, com a desmistificação de um olhar pautado por aquilo que se vê na TV ou internet. Os professores visitantes trazem uma visão pautada em suas experiências de vida, com críticas a cultura estadunidense e apresentam ainda um uso da língua relacionado com questões globais extremamente necessárias, as quais os futuros docentes podem adaptar em seus contextos.

\section{Percurso Metodológico}

Esta é uma pesquisa de natureza qualitativa que busca explicar e entender os dados, ao invés de obter resultados quantitativos (STRAUSS; CORBIN, 2008). Para tal, elaboramos e aplicamos um questionário contendo seis perguntas sobre as experiências dos estudantes de Letras Inglês com as ETAs e nas atividades desenvolvidas por elas.

Das seis questões, vamos analisar neste estudo, duas perguntas referentes à formação linguística e docente dos acadêmicos, sendo elas: 1) Você considera que a participação das ETAs em nosso curso proporcionou melhorias na sua aprendizagem de língua inglesa? Se sim, como? Se não, por que não?; 2) Você considera que a participação das ETAs em nosso curso proporcionou melhorias na sua formação como professor de língua inglesa? Se sim, como? Se não, por que não?

Como mencionamos em outros momentos, o objetivo de escolher justamente estas duas questões, deve-se ao fato de que temos a intenção de avaliar a experiência com ETAs da comissão Fulbright na formação de professores de inglês fazendo uma ponte com a internacionalização em casa.

0 questionário obteve 58 respostas, as quais analisamos por meio da análise paradigmática e sintagmática (APS) (REIS, 2018). Nesse tipo de análise, realizamos uma leitura inicial, agrupando os dados semelhantes em categorias chamadas de hiperônimos e hipônimos. Em seguida, avançamos para a análise sintagmática, que não exige uma interpretação gramatical de cunho sintático, pois está interessada nos significados e no poder da linguagem. Segundo Reis:

Em lugar de limitar as possibilidades de realização da língua sob descritores linguísticos, a APS se ocupa, na fase de análise sintagmática, com as relações que, ao expor suas interpretações, o pesquisador estabelece entre ideias que construiu na fase analítica paradigmática. Em outras palavras, a APS não tem por finalidade em relatos de pesquisa o relevo linguístico, pois está comprometida com o conteúdo e significado da linguagem e não de forma estática, previsível, pretendidamente estável, mas dependente do seu contexto de origem, da subjetividade daqueles que a interpretam, das relações de poder entre atores sociais. (REIS, 2018, p. 154).

As análises por meio da APS geram grades analíticas, que serão explicadas e interpretadas pelos pesquisadores, deixando claro que nenhuma análise é parcial, por isso, elas são feitas pelas lentes dos pesquisadores que tentam se distanciar o 
máximo possível de suas ideologias e se colocam no lugar dos participantes da pesquisa, levando em consideração o contexto. Tais grades e nossa interpretação dos dados estão dispostos na seção seguinte.

Contudo, antes de apresentar ao leitor nossos resultados de pesquisa, precisamos deixar evidente quais foram as preocupações éticas deste estudo. Levando em consideração que o questionário aplicado aos acadêmicos tinha a intenção de obter um feedback sobre as ações realizadas com as ETAs no ano de 2018 e como elas impactaram (ou não) na formação linguística e docente dos alunos, nosso objetivo era de que as respostas fossem as mais sinceras possíveis, de modo a contribuírem para o planejamento das atividades em 2019. Por isso, um dos cuidados éticos que tivemos foi a não identificação dos estudantes, para que eles emitissem suas opiniões orgânicas sobre a experiência. Ainda nesse sentido, todos os estudantes leram e assinaram um Termo de Consentimento Livre e Esclarecido (TCLE), onde puderam encontrar seus direitos enquanto participantes da pesquisa, incluindo sua liberdade de se retirar da investigação quando desejassem e de ter seus dados e identidade resguardados (optamos por chamá-los de aluno 1, aluno 2, e assim por diante).

\section{Análise dos dados}

Como mencionado anteriormente, obtivemos 58 respostas (descartando as respostas repetidas) para o questionário aplicado. Levando em consideração as questões que desejamos analisar, a primeira pergunta obteve seis não-respostas, ou seja, estudantes que não enviaram uma resposta completa ou somente digitaram algo a fim de prosseguirem para a questão seguinte. Para a segunda pergunta, o número de não-respostas subiu para nove. Sendo assim, temos 52 respostas positivas para a questão 1 e 49 respostas para a questão 2 .

Passaremos para a análise das respostas de cada pergunta separadamente, trazendo exemplos mais significativos das categorias criadas e utilizando de recursos gráficos, como o sublinhado, para evidenciar qual parte da resposta se refere à categoria de análise em discussão.

\subsection{Pergunta 1: Você considera que a participação das ETAs em nosso curso proporcionou melhorias na sua aprendizagem de língua inglesa? Se sim, como? Se não, por que não?}

Em relação à primeira pergunta, o foco era saber se o estudante percebeu melhorias na sua aprendizagem de língua inglesa por conta da participação das ETAs no curso. Primeiramente, verificamos que das 52 respostas válidas, apenas um participante citou que não houve melhorias em sua formação linguística devido ao fato de que não pode participar de todas as interações. Portanto, o conjunto de dados para a primeira pergunta soma 51 excertos.

A partir de suas respostas, fomos capazes de classificá-las em três categorias maiores (hiperônimos) que se referem à origem das melhorias percebidas pelos discentes, sendo elas: melhorias em seus conhecimentos, melhorias que causaram mudanças e melhorias que geraram comparações. Desses 
hiperônimos surgem categorias menores (hipônimos), que refletem os tipos de melhorias, tais quais: linguístico-discursivo, melhorias na compreensão oral $e$ auditiva, cultural, desenvolvimento pessoal e auto-estima, e supervalorização do falante nativo.

0 quadro a seguir, referente a pergunta 1, apresenta tais melhorias e categorias de análise escolhidas para a investigação e observação das respostas fornecidas pelos alunos. Também é possível obter a localização de cada resposta, na seção de localização das evidências, ou seja, qual aluno forneceu a resposta que se encaixa na categoria.

As categorias deste quadro foram pensadas com o intuito de avaliar o impacto do contato e aproximação entre estudantes e ETAs, nos âmbitos linguísticos, profissionais e pessoais de cada aluno.

\begin{tabular}{|c|c|c|}
\hline \multicolumn{3}{|c|}{$\begin{array}{l}\text { Você considera que a participação das ETAs em nosso curso proporcionou melhorias } \\
\text { na sua aprendizagem de língua inglesa? Se sim, como? Se não, por que não? }\end{array}$} \\
\hline$\underline{\text { ORIGEM DAS }}$ & $\underline{\text { TIPOS DE MELHORIAS }}$ & LOCALIZAÇÃO DAS EVIDÊNCIAS \\
\hline \multirow{4}{*}{ CONHECIMENTOS } & LINGUÍSTICO-DISCURSIVOS & $\begin{array}{l}\text { A24; A50; A6; A15; A28; A52; } \\
\text { A34; A56; A14; A17; A53; A51; } \\
\text { A10; A48; A11; A31; }\end{array}$ \\
\hline & \multirow[t]{2}{*}{ ORAIS E AUDITIVOS } & A24; A20; A45; A43; A42; A11; \\
\hline & & A27; A20; A43; \\
\hline & CULTURAIS & $\begin{array}{l}\text { A12; A50; A13; A38; A20; A41; } \\
\text { A52; A37; } \\
\text { A34; A58; A35; A2; A51; A16; } \\
\text { A33; }\end{array}$ \\
\hline \multirow[t]{2}{*}{ MUDANÇAS } & \multirow[t]{2}{*}{$\begin{array}{l}\text { DESENVOLVIMENTO PESSOAL E } \\
\text { AUTOESTIMA }\end{array}$} & $\begin{array}{l}\text { A47; A15; A4; A54; A55; A9; } \\
\text { A26; A46; }\end{array}$ \\
\hline & & A4; A3; A54; A1; A7; \\
\hline COMPARAÇÕES & $\begin{array}{l}\text { SUPERVALORIZAÇÃO DO FALANTE } \\
\text { NATIVO }\end{array}$ & A57; A6; A36; A18; A32; A7; \\
\hline
\end{tabular}

Quadro 1 - Categorias de análise referentes à pergunta 1.

Fonte: as autoras (2021).

\subsubsection{Conhecimentos}

Dentro do hiperônimo conhecimentos, ou seja, qual melhoria na aprendizagem de língua inglesa o aluno percebeu com a participação das ETAs no curso, conseguimos identificar três categorias (ou hipônimos). Nesse sentido, os participantes da pesquisa dissertaram sobre melhorias de conhecimento linguístico discursivo, orais e auditivos e culturais.

No que diz respeito à primeira categoria, onde os alunos falaram sobre as melhorias nos seus conhecimentos linguístico-discursivos, percebemos uma ligação 
com as questões de vocabulários e informações linguísticas adquiridas por meio da interação com as falantes nativas ${ }^{3}$ do idioma. Os trechos ${ }^{4}$ a seguir trazem alguns exemplos:

... A interação do ETAs fez com que pudesse ter uma visão mais ampla do inglês e não ficar preso apenas na gramática padrão da língua (...) (A10)

Sim, pois com a ajuda delas consegui me adaptar melhor ao sotaque e ao modo que os nativos falam, também contribuiu bastante para aumentar o meu vocabulário (...) (A15)

Senti uma significativa melhora na minha oralidade e na parte do listening. (A43)

Sim, elas nos ajudaram com aplicação de vocabulário adequado para o contexto, temas transversais (...) (A50)

Devido ao contato direto com falantes nativos de inglês, houve muitas nuances e detalhes linguísticos que pude sanar. Esse fator, juntamente com a oportunidade ideal de fazer o uso do inglês durante meus horários acadêmicos resultou em uma melhoria significativa na aprendizagem do meu inglês. (A56)

É possível identificar que os estudantes viram melhorias no quesito de conhecimentos linguísticos-discursivos, pois em suas respostas aparece a valorização desse contato e do ensino e aprendizagem de vocabulários, expressões linguísticas, gírias, sotaques, conhecimentos práticos da língua, e até o uso mais constante do idioma, etc. Os alunos parecem relacionar essa melhoria com a participação das estrangeiras, como se o professor formador (não nativo) não fosse capaz de oferecer tais informações, o que é, de certa forma, compreensível, uma vez que elas trouxeram o olhar e costumes de fora e falavam apenas em inglês com os alunos, inclusive em momentos externos à sala de aula.

Prosseguindo para a seguinte categoria, a qual foca nos conhecimentos orais e auditivos, pudemos perceber que muitos acadêmicos relacionaram a participação das ETAs à melhorias em suas habilidades de speaking e listening. Para eles:

Com toda certeza sim. Principalmente quanto à pronúncia, elas nos ajudaram muito no Speaking, como apresentar algo mais natural, como soar mais natural, etc. (A5)

Sim, o uso contínuo da língua unido com as aulas teóricas proporcionadas pelo curso trouxeram enorme evolução para minha oralidade e escrita do idioma, melhorando assim meus métodos de aprendizagem em inglês. (A11)

\footnotetext{
${ }^{3}$ Recebemos duas professoras assistentes do sexo feminino no ano de 2018.

${ }^{4}$ Os trechos sublinhados significam que tal parte da resposta especificamente é a que se refere à categoria de análise.
} 
Sim. A participação das ETAs ajudou muito na resolução de dúvidas, no aperfeiçoamento do listening e da pronúncia. (A20)

Sim , ter a experiência de precisar me comunicar em inglês com as ETA's foi um ótimo exercício de oralidade, eu realmente senti que pude melhorar minha comunicação e desenvolver vários aspectos relacionados à língua inglesa. (A45)

Nesse sentido, notamos que os estudantes foram capazes de perceber avanços na sua formação linguística, especialmente no que concerne à oralidade e a audição, por conta da participação das ETAs no curso. Isso pode ter acontecido, pois, para eles, compreender e ser compreendido por um falante nativo da língua inglesa, ou seja, ter a aprovação que esse contato propicia, lhes oferece uma sensação de desenvolvimento.

Outro ponto bastante citado pelos acadêmicos foi o conhecimento cultural resultante das interações com as ETAs. Relativo a isto, vale frisar que o objetivo da comissão Fulbright com este programa de intercâmbio é, justamente, de disseminar o idioma e também a cultura estadunidense nos países. Por isso, muitas atividades de cunho cultural foram programadas pelas coordenadoras do programa na universidade juntamente com as ETAs. Aconteceram palestras quinzenais sobre aspectos culturais dos Estados Unidos, workshops sobre como ensinar tais assuntos, celebração de datas comemorativas e inclusão de tópicos culturais nos encontros dos clubes de conversação e nos momentos de co-teaching em algumas disciplinas. Os alunos comentaram:

Sim, maior compreensão da cultura americana. (A2)

Em relação a aprendizagem da cultura americana foi bem interessante pois aprendemos um pouco mais e além disso coisa que eu não conhecia. (A12)

Sim, a melhor forma de se entender uma cultura é tendo pessoas que fazem parte dela ao seu redor. (A13)

Sim, elas nos ajudaram com aplicação de vocabulário adequado para o contexto, temas transversais e cultura foram muito abrangentes para com a língua, costumes etc. (A50)

Tais opiniões podem ser interpretadas pelo fato de que, na cidade onde a universidade se localiza, há pouca vinda de estrangeiros e o contato com outras culturas se dá pelas tradições de pioneiros, imigrantes, mas poucas vezes diretamente com alguém de outra nacionalidade. Além disso, como já mencionado, o público desta universidade se concentra nas classes sociais média baixa e baixa, levando-os a ter poucas oportunidades de realizar um intercâmbio, uma viagem de qualquer tipo a outro país ou até mesmo pelo Brasil. Portanto, entendemos essa valorização dos conhecimentos culturais proporcionados pela relação com as ETAs, haja vista que, para muitos, é uma experiência única, desafiadora, enriquecedora e benéfica. 
É possível notar também que os acadêmicos veem uma indissociabilidade entre o aprendizado de um idioma com questões culturais relativas aos países onde tal idioma é língua materna. 0 inglês, contudo, é uma língua global, que já não pertence a um país específico, por isso, faz-se primordial relacionar a cultura estadunidense com diversas outras culturas, inclusive a brasileira, fato que foi bastante explorado e valorizado nas atividades realizadas com as ETAs.

\subsubsection{Mudanças}

Seguindo para as melhorias com origem nas mudanças citadas pelos alunos, muitos deles argumentaram que a participação das ETAs lhes proporcionou desenvolvimento pessoal e autoestima. Vejamos nos exemplos que seguem:

Sim. Como citado anteriormente, o contato com falantes nativos nos coloca em situação real de comunicação em língua inglesa, $\underline{0}$ que nos faz desenvolver uma maior criticidade quanto ao nosso desenvolvimento e processo de aprendizagem, isto é, se este processo está sendo bem delineado ou se há lacunas a se preencher. (A7)

Sim, conversar com elas deu um pouco mais de confiança para utilizar o inglês em público quando devido. (A9)

Muito, a participação das ETAs me trouxe a oportunidade de pela primeira vez ter um contato mais próximo com falantes nativos de inglês, então tive que me esforçar para falar somente em inglês e prestar muita atenção no que elas falavam. (A47)

Sim, pois eu tinha vergonha de falar inglês e ao conviver com elas eu pude perceber que eu tinha um bom domínio da língua. (A54)

Pelas respostas supracitadas, é possível identificar que os acadêmicos de Letras Inglês conseguiram notar em si mesmos mudanças em relação a seu domínio da língua, pois sentiam-se mais seguros ao falar no idioma. Além disso, alguns comentários vêm acompanhados de uma autoavaliação em relação ao próprio processo de aprendizagem do inglês, onde eles conseguiram notar avanços, lacunas e compreender a necessidade de prática da língua.

\subsubsection{Comparações}

A última categoria referente a esta pergunta de pesquisa está relacionada às melhorias no campo das comparações, ou seja, excertos em que os acadêmicos fazem uma supervalorização do falante nativo, mas que, de certa forma, os auxiliou em seu desenvolvimento linguístico. Seguem alguns trechos de exemplo:

Sim. Como citado anteriormente, o contato com falantes nativos nos coloca em situação real de comunicação em língua inglesa... (A7) 
Sim, pois com a ajuda delas consegui me adaptar melhor ao sotaque e ao modo que os nativos falam... (A15)

Sim, ter um falante, alguém que tenha um conhecimento real sobre a língua, faz com que haja maior interesse uma maior aprendizagem sobre. (A18)

Com certeza. Achei que ajudaram a desenvolver principalmente minha capacidade de entender o inglês nativo... (A52)

É importante salientar que, nesta categoria, aparecem dois tipos de respostas: 1) acadêmicos que, viram no falante nativo uma oportunidade de aprimorar suas habilidades da língua e de cultura (vide A15 e A52), uma vez que o encontro com diferentes idiomas e culturas é sempre enriquecedor e; 2) estudantes que supervalorizam o contato com o estrangeiro colocando-o em um pedestal, como se, somente ele fosse o detentor de um inglês dito "real", "verdadeiro" (como A7 e A18).

No que tange o último posicionamento, é necessário frisar que este não é um dos objetivos da internacionalização (em casa), pelo contrário, pesquisadores da área (IÑIGUEZ, 2011; MIKULEC, 2014; AGNEW; KAHN, 2014; JORGE, 2018) tem advogado a favor da internacionalização como forma de se incentivar a pluralidade, o multiculturalismo, tornando este processo uma via de mão dupla, onde ambos os países e agentes envolvidos trocam conhecimentos e se beneficiam desta ação. Dessa maneira, não existe um detentor do idioma, o inglês do falante nativo não deve ser visto como melhor do que o do docente que o têm como língua estrangeira, e muito menos a língua inglesa deve ser vista como superior, mais importante ou mais útil do que a própria língua materna. Internacionalização é também sobre enaltecer e divulgar a cultura local.

Todavia, somos capazes de entender os motivos pelos quais os alunos valorizam tais experiências, isso se dá justamente por não terem tantas oportunidades de internacionalizar, por isso, tendem a supervalorar o que vem do outro, de fora. Ademais, há, constantemente este discurso, sobretudo na mídia, de que o inglês do falante nativo é o correto, que aprender com o falante nativo é o ideal, fazendo com que muitas pessoas acreditem nesse posicionamento.

Ainda é válido pontuar que as ETAs que trabalharam no campus no período letivo analisado eram extremamente abertas e teciam críticas embasadas sobre os pontos com os quais discordavam acerca da cultura ou sistema estadunidense, bem como enalteciam as qualidades de seu país. 0 propósito da internacionalização é justamente esta troca cultural, esta capacidade de ser crítico e enxergar pontos positivos e negativos sobre aspectos culturais, linguísticos, sociais e políticos que compõem uma nação.

Por outro lado, obtivemos uma parcela de respostas, nas quais alguns estudantes perceberam a participação das ETAs como uma oportunidade de lidar com um sotaque, uma variante diferente do idioma, realizando adaptações e desenvolvendo habilidades que contribuíram com sua formação linguística.

Estas foram as categorias relacionadas à primeira pergunta de nosso estudo, focando na formação linguística dos futuros professores de inglês. 
Seguiremos para a análise das respostas acerca da questão sobre melhorias na formação docente dos acadêmicos.

3.2 Pergunta 2: Você considera que a participação das ETAs em nosso curso proporcionou melhorias na sua formação como professor de língua inglesa? Se sim, como? Se não, por que não?

Como já mencionado, a segunda pergunta que trouxemos para investigação procurava avaliar se houve desenvolvimento ou mudanças em relação ao aspecto profissional dos estudantes. Das 49 respostas obtidas, dois estudantes mencionaram ver melhorias parciais em sua formação docente, um deles citou que não pode participar das atividades voltadas à prática docente e outro comentou que via a melhoria (ainda com pouca certeza) apenas por ser o contato com um falante nativo. Outro aluno ainda disse que não houve melhoria na sua formação como professor, mas na continuação de sua resposta disserta auxílio das ETAs em sua melhoria na fluência da língua e acerca de pontos gramaticais, o que caracteriza, a nossa ver, uma resposta contraditória, que pode ser analisada como positiva. Portanto, analisamos, para a questão 2, 47 excertos.

Foi possível classificar as respostas em duas categorias que demonstram a origem das melhorias, as quais advêm de melhorias no campo dos conhecimentos e melhorias no campo das mudanças. Dos hiperônimos, classificamos os tipos de melhorias em seis categorias, sendo elas: teórico-metodológicos, habilidades do idioma, cultural, desenvolvimento pessoal, auto-avaliação, e identidade profissional.

0 quadro a seguir, referente a pergunta 2 , tem como foco a análise das respostas dos estudantes considerando suas percepções em relação a sua vida profissional, no campo teórico e prático da docência da língua inglesa.

\begin{tabular}{|c|c|c|}
\hline \multicolumn{3}{|c|}{$\begin{array}{l}\text { Você considera que a participação das ETAs em nosso curso proporcionou melhorias } \\
\text { na sua formação como professor de língua inglesa? Se sim, como? Se não, por que } \\
\text { não? }\end{array}$} \\
\hline$\frac{\underline{\text { ORIGEM DAS }}}{\underline{\text { MELHORIAS }}}$ & TIPOS DE MELHORIAS & LOCALIZAÇÃO DAS EVIDÊNCIAS \\
\hline \multirow{3}{*}{ CONHECIMENTOS } & TEÓRICO-METODOLÓGICOS & $\begin{array}{l}\text { A1; A4; A8; A11; A16; A17; A20; } \\
\text { A21; A24; A26; A28; A31; A33; } \\
\text { A36; A37; A39; A43; A46; A48; } \\
\text { A49; A51; A53; A54. }\end{array}$ \\
\hline & LINGUÍSTICOS & $\begin{array}{l}\text { A4; A6; A7; A8; A12; A13; A15; } \\
\text { A18; A21; A42; A45; A52; A } 58 .\end{array}$ \\
\hline & CULTURAIS & $\begin{array}{l}\text { A3; A15; A18; A21; A26; } \\
\text { A35; A42; A } 45 ; \text { A } 47 .\end{array}$ \\
\hline MUDANÇAS & DESENVOLVIMENTO PESSOAL & $\begin{array}{l}\text { A5; A7; A10; A14; A28; A40; } \\
\text { A42; A44; A 50; A57; A } 58 .\end{array}$ \\
\hline
\end{tabular}


Quadro 2 - Categorias de análise referentes à pergunta 2.

Fonte: as autoras (2021).

\subsubsection{Conhecimentos}

Dentro do hiperônimo conhecimentos, procuramos entender o tipo de melhoria que os estudantes puderam notar em sua formação como professores de língua inglesa através da participação das ETAs no curso. Conseguimos identificar três categorias (hipônimos). São elas: conhecimentos teórico-metodológicos, linguísticos e culturais.

Em relação à primeira categoria, onde os alunos relataram suas melhorias em seus conhecimentos teórico-metodológicos, é possível observar como os estudantes aplicaram novas informações adquiridas através do contato com as ETAs, em seus contextos profissionais, de modo que pudessem se beneficiar da experiência. Os trechos a seguir contém alguns exemplos:

Sim, porque a abordagem delas foi diferente e algo que posso utilizar em minhas aulas quando estiver exercendo (A1)

Muito, elas trouxeram novas metodologias e atividades muito interessantes para serem aplicadas em sala de aula. (A24)

Sim, pois o conhecimento obtido pelas aulas de ambas, você pode introduzir algo parecido para seus alunos (A36)

Através destes exemplos, fica claro como os estudantes procuraram relacionar suas experiências com as ETAs, com suas experiências profissionais, seja em um momento que já vivenciavam, ou em um futuro próximo como professores de língua inglesa. Para eles, ver diferentes metodologias em prática, e estar no papel de aluno, proporcionou uma maior confiança e ânimo para trazer as mesmas práticas para suas próprias aulas. Isto também demonstra uma grande estima e apreciação por parte dos estudantes em relação aos novos conhecimentos apresentados.

Seguindo para a próxima categoria, a qual foca nos conhecimentos linguísticos, também é possível notar como os alunos relacionaram a participação das ETAs com melhorias em suas habilidades linguísticas, ou seja, speaking, listening, writing and reading. Para eles:

Sim, pude melhorar meu vocabulário e a forma como ensino (A4)

Como professor, não exatamente, elas auxiliaram a obter uma fluência maior ao falar inglês e ajudaram em pontos gramaticais. (A6) 
Sim. Os usos reais da língua inglesa ficam mais evidentes quando estamos em contato com as ETAs (A7)

(...) as ETAs vieram para ajudar na compreensão auditiva. (A12)

Neste quesito, podemos notar um grande desenvolvimento sentido pelos alunos em relação à sua formação linguística em todas as habilidades. Também é possível observar que para eles, ser um bom professor de línguas está diretamente relacionado a um grande conhecimento da língua inglesa em si. Apesar de termos uma pergunta no questionário focada somente no desenvolvimento linguístico, os estudantes repetiram a importância das melhorias em relação às quatro habilidades do idioma também na questão sobre a formação docente, fato que corrobora com a análise supracitada, pois demonstra a valorização dos conhecimentos linguísticos para o desempenho da função de professor de língua inglesa.

Outro tópico muito citado pelos acadêmicos foi o de conhecimentos culturais, propiciado pelo contato e interação com as ETAs. Segundo eles:

Sim, tendo contato com elas tive um melhor aproveitamento para tirar as dúvidas sobre a outra cultura e o uso da língua. (A3)

Sim, ter vivido essa experiência, ter aprendido mais sobre a língua inglesa, e ver mais da cultura sobre olhar delas foi realmente importante. (A18)

Sim. Pois a convivência com elas, ajuda a quebrar alguns tabus sobre os norte americanos na sala de aula. (A35)

Sim, melhorando minha oralidade e expandindo meus conhecimentos culturais com certeza estou me formando uma melhor professora. (A45)

Creio que ambas ajudaram muito a desenvolver um conhecimento maior e mais contextualizado sobre cultura americana... (A47)

A partir de tais excertos, podemos observar como os estudantes consideram o contato com nativos muito enriquecedor quando se trata do aprendizado da cultura estadunidense. Também é possível notar a relação feita entre ser um bom docente e ter um vasto conhecimento sobre a cultura referente ao ensino da língua ensinada. Isso pode ser atribuído ao fato de que, como já citado na análise da pergunta anterior, os alunos veem uma indissociabilidade no ato de ensinar ou aprender uma língua e sua cultura.

\subsubsection{Mudanças}

0 próximo hiperônimo referente à pergunta 2 de nossa pesquisa está relacionado com as mudanças sentidas pelos acadêmicos no âmbito da docência. 
Muitos citaram o desenvolvimento pessoal como uma das principais mudanças,' como podemos ver nos exemplos a seguir:

Sim, aprendi a não ter medo ou vergonha de usar meu inglês. (A28)

Com certeza, me senti segura e pude treinar o idioma com tranquilidade. (A40)

Sim, bastante. A experiência que tive com elas me trouxe novos olhos pra saber lidar com situações e sentimentos que ainda eram um problema. (A57)

(...) perder um pouquinho de vergonha de falar em inglês. (A58)

Com base nas respostas, podemos identificar que os estudantes sentiram melhorias em várias áreas de suas vidas pessoais, como aumento na confiança para falar a língua inglesa, e maior segurança para cometer erros e praticar a língua da forma que desejar. Isso nos mostra ainda que, tal confiança e segurança nos aspectos linguísticos são valorizados pelos acadêmicos como características de um professor de língua inglesa.

Por fim, a última categoria de nossa análise, onde os alunos comentam sobre as mudanças percebidas em sua identidade profissional, é possível observar como a experiência com as ETAs impactaram suas percepções de si próprios como futuros professores da língua inglesa, como constam nos seguintes exemplos:

A minha segurança melhorou bastante ao estar envolvida e não ser vista apenas como aluna, mas como aprendiz e futura professora. (A10)

(...) um falante melhor também pode ser um professor melhor na minha visão (A13)

Sim, aprendi com elas como o entusiasmo e a paixão ao falar sobre determinado assunto faz com que os alunos se dediquem mais e prestem mais atenção. (A27)

Sim, me sinto mais apto para lecionar sabendo que o meu inglês não é diferente de um nativo. (A44)

Pude enxergar com novos olhos a dinâmica de ser professor e o quanto é bom trabalhar com algo que se gosta pra valer. (A57)

Neste sentido, podemos concluir que o contato com as ETAs proporcionou a oportunidade para que os acadêmicos saíssem do papel de alunos, e se enxergassem também no papel de professores, o que gerou um aumento significativo em sua confiança e senso de capacidade para realizar o trabalho de ensino da língua inglesa. Obter reconhecimento de um falante nativo sobre suas 
habilidades linguísticas parece ser muito importante para eles, dando segurança para seguirem na carreira docente.

\section{Considerações finais}

Este estudo teve como objetivo avaliar a experiência com English Teaching Assistants (ETAs) da comissão Fulbright na formação de professores de inglês após o primeiro ano de execução do projeto em uma universidade estadual do Paraná fazendo uma ponte com o conceito de internacionalização em casa. Realizou-se uma análise paradigmática e sintagmática (APS) das respostas de duas perguntas sobre o impacto da participação das ETAs na formação linguística e docente dos acadêmicos. Em sua grande maioria, os estudantes avaliaram que houve um impacto positivo nessa participação, detalhando os motivos para tal percepção.

Concluímos também que a ação em parceria com a Fulbright contribuiu para os avanços do processo de internacionalização do campus onde foi executada, pois ofertou aos estudantes uma oportunidade de internacionalização em casa. Ainda nesse sentido, acreditamos que parcerias bem executadas e com objetivos de justiça social, tendo em mente as dinâmicas do imperialismo linguístico do inglês e com foco em uma visão decolonial do ensino e aprendizagem do idioma, podem resultar em uma formação de futuros professores de inglês mais conscientes sobre o papel desse idioma no mundo e engajados em mudanças de perspectivas. Temos ciência que a internacionalização no Brasil ainda não é uma via de mão dupla, por mais que tenha sido divulgada dessa forma, por muitos anos, o que se vê é um controle e beneficiamento de países do hemisfério norte (MOLINARI; FRANCO; PASSONI, 2020).

Sabemos que a experiência aqui citada possui cunho imperialista, pois vem com grandes objetivos de disseminação de cultura estadunidense, mas acreditamos fortemente que é possível tornar esse ponto negativo em uma oportunidade de crítica e reflexão por parte dos envolvidos. Temos como meta, ao nos candidatarmos a essas parcerias, o mesmo que Mikulec:

A internacionalização do ensino tem o potencial de impactar não
somente a comunidade global, mas a comunidade local na qual os
professores trabalham também. Ao incorporar perspectivas
globais à formação de professores, as instituições não só
impactam os novos professores, mas por extensão, os estudantes e
comunidades nas quais eles servem. (MIKULEC, 2014, p. 5)
(tradução nossa)

Portanto, mesmo com tantos pontos a se considerar sobre tal interação, compreendemos o quão importante foi essa socialização entre os estudantes de Letras Inglês da Unespar campus Apucarana com as ETAs que participaram do curso no ano de 2018 para suas formações nos âmbitos linguísticos e pedagógicos e pela oportunidade de internacionalização em casa. 
AGNEW, Melanie; KAHN, Hilary E.; Internationalization at home: grounded practices to promote intercultural, international, and global learning. Metropolitan Universities. v. 25, n. 3, p. 31-46, 2014.

BAUMVOL, Laura Knijnik.; SARMENTO, Simone.; A internacionalização em casa e o uso do inglês como meio de instrução. Echoes. Future Reflections on Language and Literature, Florianópolis, p. 65-82, 2016.

DE WIT, Hans. Internationalisation of higher education, an introduction on the why, how and what. DE WIT, Hans (Ed.) An Introduction to Higher Education Internationalisation. Vita e Pensiero. 2013. p. 13-46.

DE WIT, Hans; LEAL, Fernanda; UNANGST, Lisa; Internationalization aimed at global social justice: Brazilian universities initiative to integrate refugees and displaced populations. XLIV Encontro da ANPAD - EnANPAD 2020, p. 1-18, 2020.

HUDZIK, John K. Comprehensive Internationalization: from concept to action. NAFSA publications. 2011.

IÑIGUEZ, Alma Arcelia Ramírez; Conditions for the Internationalisation of Higher Education: Between Inclusion and Exclusion in a Globalised World. Revista de Universidad y Sociedad del Conocimiento, v. 8, n. 2, p. 313-325, 2011.

JORGE, Miriam Lúcia dos Santos. Internacionalização em casa e educação para cidadania global: primeiras aproximações. In: VIANNA, Rachel de Sousa; LARANJEIRAS, Delzi Alves (Orgs); Internacionalização do Ensino Superior - concepções e experiências. Editora UEMG. 2018. p. 36-45.

KNIGHT, Jane. Updating the definition of internationalization. International Higher Education, 2003. p. 2-3.

KNIGHT, Jane. Five myths about internationalization. International Higher Education, v. 62, p. 14-15, 2011.

KNIGHT, Jane. Five truths about internationalization. Centre for International Higher Education, v.69, p. 4-5, 2012.

MAUÉS, Olgaíses Cabral; BASTOS, Robson dos Santos. Políticas de internacionalização da Educação Superior: o contexto brasileiro. Educação, v. 40, n. 3, p. 333-342, 2017.

MIKULEC, Erin. Internalization and teacher education: what dispositions do teachers need for global engagement? Education in a changing society, v. 1, p. 5-13, 2014.

MOLINARI, Andressa Cristina; FRANCO, Sandra Aparecida Pires; PASSONI, Taisa Pinetti. Formação de professores de línguas em contexto de internacionalização. Revista NUPEM, Campo Mourão, v. 12, n. 26, p. 62-80, 2020.

REIS, Simone. Análise paradigmática e sintagmática em pesquisa qualitativa com dados de linguagem humana. Signum: Estudos da Linguagem, v. 21, n. 2, p. 147-171,2018.

ROBSON, Sue. Internationalization at home: internationalizing the university experience of staff and students. Educação, Porto Alegre, v. 40, n. 3, p. 368-374, 2017. 
STRAUSS, Anselm; CORBIN, Juliet. Pesquisa qualitativa: técnicas e procedimentos para o desenvolvimento de teoria fundamentada. 2. ed. Porto Alegre: Artmed, 2008.

\section{Para citar este artigo}

D’ALMAS, Juliane; CALDAS, Ana Cláudia; GUIDES, Jaqueline Such de Melo. Internacionalização em casa e a formação de professores de inglês: avaliação de uma experiência com ETAs. Miguilim - Revista Eletrônica do Netlli, Crato, v. 10, n. 4, p. 16921711, nov.-dez. 2021.

As autoras

Juliane D'Almas é Mestre e Doutora em Estudos da Linguagem pela Universidade Estadual de Londrina (UEL) e professora adjunta na Universidade Estadual do Paraná (Unespar), campus Apucarana.

Ana Cláudia Caldas é acadêmica do curso de Letras Inglês da Universidade Estadual do Paraná (Unespar), campus Apucarana, e docente em escolas públicas e privadas do município de Apucarana, PR.

Jaqueline Such de Melo Guides é egressa do curso de Letras Inglês da Universidade Estadual do Paraná (Unespar), campus Apucarana, e docente em escolas públicas e privadas do município de Faxinal, PR. 